\title{
ESTRESSE DE MINORIA EM NARRATIVAS DE VIDA DE HOMENS GAYS NO YOUTUBE
}

\author{
Venan Lucas de Oliveira Alencar ${ }^{1}$
}

Resumo: Por meio das narrativas de vida, é possível denunciar, expor, evidenciar problemas inerentes não só ao indivíduo que narra, mas também à comunidade de que participa. Neste estudo, partimos da Análise do Discurso (AD) de vertente francesa para analisarmos duas narrativas de vida disponíveis em vídeos no YouTube. Além da análise da linguagem verbal, buscamos traçar paralelos com a linguagem não verbal utilizando como ferramenta a Grade de Análise de Imagens proposta por Mendes (2013). Assim, nossa pesquisa parte de um viés linguístico e imagético atravessado por questões de gênero e sexualidade. Para tratar dessas questões, autores como Halperin (1995, 2012), Foucault (1978, 1978a) e Hottes et al. (2016) serão parte de nossas referências. Em relação às narrativas de vida, partimos das considerações de Machado (2015, 2016), cuja abordagem amplia nossas noções sobre o tema e nos permite ir além da materialidade linguística. Por fim, esperamos que essa breve análise lance uma luz sobre as formas de vida constrangidas dos sujeitos minorizados em questão para que, com sorte, possamos aprofundarmos nas particularidades inerentes a nossas formas de vida, questionando-as e trazendo à superfície questionamentos talvez ainda improváveis.

Palavras-chave: Análise do discurso, Narrativa de vida, Estresse de minoria, YouTube.

\section{INTRODUÇÃO}

As narrativas de vida têm se tornado relevantes nos Estudos da linguagem, Históricos e Sociológicos, de forma geral, por se tratarem de ferramentas potencializadoras de acesso a questionamentos muito atuais. Esses questionamentos são reveladores, pois evidenciam traços e denunciam problemas sociais que dizem respeito à comunidade de que participa o narrador e, por esse motivo, ampliam nosso entendimento sobre as formas de vida daquele grupo social.

\footnotetext{
${ }^{1}$ Mestre e Doutorando em Estudos Linguísticos na Faculdade de Letras da Universidade Federal de Minas Gerais (UFMG).

Vol. 03, N. 11, Jul. - Set., 2020 - http://periodicoscientificos.ufmt.br/ojs/index.php/rebeh/index
} 
Neste estudo em específico, partimos da análise de duas narrativas que, na verdade, fazem parte de um corpus mais extenso da tese do autor. Transcrevemos essas narrativas, que estavam disponíveis no YouTube, e analisamos não só a parte verbal, como também a não verbal. Para isso, utilizamos alguns elementos da Grade de Análise de Imagens proposta por Mendes (2013) (vide Quadro 1). Acreditamos que a linguagem não verbal desempenha um papel importante na significação, pois é por meio dela que se causam efeitos de sentidos que podem estar em conformidade ou inconformidade com o que o narrador idealizou.

\begin{tabular}{|c|c|c|}
\hline \multirow{10}{*}{ ESTRATO ICÔNICO } & \multirow{3}{*}{ Dimensão Situacional da Imagem } & Sujeitos do Discurso (Euc, Eue, Tud e TUi) \\
\hline & & Gêrero e Estatuto (factual, ficcional) \\
\hline & & Efeitos (real, ficção ou gênero) \\
\hline & \multirow[t]{3}{*}{ Elementos Técnicos da Imagem Cinética } & $\begin{array}{l}\text { Elementos Plásticos (Cores, P\&B, imagem digital ou analógica, } \\
\text { captação em super } 8,16 \mathrm{~mm} \text { ou dispositivos móveis) } \\
\text { Planos e ângulos(geral, total, médio, plano americano, primeiro } \\
\text { plano, plano detalhe) }\end{array}$ \\
\hline & & Pontos de vista \\
\hline & & $\begin{array}{l}\text { Estrato sonoro/musical (ruidos, musica ambiente e outros } \\
\text { elementos significantes) }\end{array}$ \\
\hline & \multirow{4}{*}{ Dimensão Discursiva e de Efeitos } & Modos de Organização (descritivo, narrativo, argumentativo) \\
\hline & & Imaginários sociodiscursivos \\
\hline & & Elementos etóticos \\
\hline & & Efeitos patêmic os visados (pathos) \\
\hline \multicolumn{3}{|c|}{ Dados de apoio paraimagéticos } \\
\hline \multirow{10}{*}{ ESTRATO VERBAL } & \multirow{3}{*}{ Dimensão Situacional da Imagem } & Sujeitos do Discurso (Euc, Eue, Tud e TUi) \\
\hline & & Gêrero e Estatuto (factual, ficcional) \\
\hline & & Efeitos (real, ficção ou gênero) \\
\hline & \multirow{3}{*}{ Categorias de língua (e organização enunciativa) } & Alocução, delocução e elocução \\
\hline & & Modalizadores e marcadores \\
\hline & & Outras categorias pertinentes à análise \\
\hline & \multirow{4}{*}{ Dimensão Discursiva e de Efeitos } & Modos de Organização (descrifivo, narrativo, argumentativo) \\
\hline & & Imaginários sociodiscursivos \\
\hline & & Elementos etóticos \\
\hline & & Efeitos patêmicos visados (pathos) \\
\hline
\end{tabular}

Quadro 1: Grade de Análise de Imagens.

Fonte: MENDES, E. Análise do discurso e iconicidade: uma proposta teórico-metodológica. In: Imagem e Discurso. Mendes, E. (coord.) Belo Horizonte: FALE/UFMG, 2013.

Tendo como suporte a teoria de Charaudeau (2003), entendemos que um narrador, ou um usuário do YouTube que publica seu vídeo narrando sua vida, é um sujeito-comunicante (EUc), ou seja, um sujeito psicossocial, empírico, atravessado por discursos que, de certa forma, "moldam" sua experiência e sua discursividade. Para termos acesso a esse sujeito, partimos do que ele projeta enquanto sujeito de palavra: Vol. 03, N. 11, Jul. - Set., 2020 - http://periodicoscientificos.ufmt.br/ojs/index.php/rebeh/index 
trata-se de seu sujeito-enunciador (EUe), um sujeito que se projeta naquela situação de comunicação específica. Sabemos, ainda, que esse sujeito fala para alguém. O público de um YouTuber faria parte do que o autor denomina sujeito-destinatário (TUd), que é imaginado, idealizado pelo sujeito que narra. Contudo, é provável que nem todos assistam de fato ao vídeo publicado; apenas aqueles que visualizaram e realizaram um trabalho cognitivo para entender o conteúdo é que são chamados sujeitos-interpretantes (TUi).

A partir dessa breve explanação, podemos seguir para a discussão sobre o estresse de minoria e sobre nossas metodologias. A partir de uma grande seleção de vídeos no YouTube, ao qual tivemos acesso buscando na ferramenta de busca da página por "estresse de minoria gay", "dificuldades ser gay", "sair do armário", "gay minority stress", "struggle being gay", "coming out gay", resgatamos dois, da totalidade do corpus, para este estudo em específico. A partir disso, realizamos a transcrição desses dois vídeos e elencamos alguns temas que se repetiam nas duas narrativas de vida. Esses temas, além de coincidentes, estavam também presentes em nossas referências, ou seja, eram tratados por pesquisadores e pesquisadoras da área de gênero, sexualidade e linguagem. $\mathrm{O}$ estresse de minoria foi um problema comum a todos esses temas, pois ele era resultado de uma série de situações e reflexões acerca da experiência de vida gay, como episódios de "bullying" na adolescência e a ilusão de "saída do armário", por exemplo.

A análise imagética foi embasada na Grade de Análise de Mendes (2013)2, que busca abranger tanto a linguagem verbal como a não verbal, numa abordagem transdisciplinar que parte sobretudo dos Estudos da Linguagem. Trata-se de um método bastante interessante, ao nosso ver, quando estamos diante de um corpus multimodal, pois graças à grade foi possível traçar diálogos entre o que era mostrado e o que era dito.

Assim, este estudo está organizado de modo que, de início, apresentamos algumas considerações a respeito da narrativa de vida e da Análise do Discurso que praticamos. Em seguida, falamos brevemente sobre o estresse de minoria e suas

\footnotetext{
2 Por motivos de restrição de espaço, não teceremos longas explanações acerca dos elementos dessa grade. Convidamos, no entanto, leitores e leitoras para a leitura de Mendes (2013), onde consta a explicação de cada elemento detalhadamente. Vide Quadro 1 e Referências.

Vol. 03, N. 11, Jul. - Set., 2020 - http://periodicoscientificos.ufmt.br/ojs/index.php/rebeh/index
} 
intersecções com as homossexualidades masculinas. Mais adiante, apresentamos e discutimos os temas abordados por nossos narradores baseados nos estudos de gênero e sexualidade e na Grade de Análise de Imagens de Mendes (2013). Por fim, delineamos alguns comentários conclusivos sobre este estudo e provocações para estudos futuros.

\section{AS NARRATIVAS DE VIDA NA PERSPECTIVA DA ANÁLISE DO DISCURSO}

A Análise do Discurso (AD) que praticamos tem suas origens em diferentes áreas do conhecimento. Seu caráter inquestionavelmente transdisciplinar é algo que deve ser usado a favor dos analistas do discurso, cujas pesquisas ultrapassam a materialidade linguística para se lançarem em domínios como da Filosofia e da Sociologia.

Patric Charaudeau, um dos proeminentes analistas do discurso contemporâneos, nos encoraja a usufruir dos benefícios dessa amplitude de possibilidades que a AD nos oferece e reconhece que sua Teoria Semiolinguística é antropofágica. Isso quer dizer que ela se apropria, em bons termos, de outras teorias para compreender os fenômenos da linguagem. A nós, pesquisadores da área, nos resta então navegar nessa multitude teórica; não nos esquecendo, em contrapartida, de que a linguagem é nosso elementobase.

As narrativas de vida, por sua vez, são o tema de pesquisa em diversas áreas do conhecimento. Machado (2015) defende a ideia de que "narrativa de vida" seria o melhor termo para caracterizar esse diálogo entre a Semiolinguística de Charaudeau e o "relato de vida", que tem suas bases na Sociologia e Antropologia. Contudo, são esses mesmos domínios que Charaudeau utilizou, e ainda utiliza, para fundamentar sua pesquisa. Portanto, faz sentido que façamos uso desse termo, pois ele expressa tanto uma historicidade, como uma filiação teórica profícuas e condizentes. Em que consistira, então, essas narrativas?

As narrativas são exercícios da memória. Rememorar fatos e experiências podem ser momentos de reavaliação - de constrangimentos, de alegrias, de tristezas. Trata-se, para Machado (2016, p. 122), de vozes que “'falam” de acontecimentos pessoais, vividos pelo indivíduo em pauta, mas também de acontecimentos coletivos dos quais o indivíduo participou de uma forma ou de outra". Essa coletividade nos Vol. 03, N. 11, Jul. - Set., 2020 - http://periodicoscientificos.ufmt.br/ojs/index.php/rebeh/index 
interessa muito, pois é por meio desse relato individual que acedemos a problemáticas que dizem respeito a um grupo maior, representado, no caso desta pesquisa, por homens gays que disponibilizaram suas narrativas no YouTube.

Butler (2015, p. 136) entende que o ato de narrar a si mesmo excede o agora e a própria capacidade narrativa: “Quando o 'eu' busca fazer um relato de si mesmo, pode começar consigo, mas descobrirá que esse 'si mesmo' já está implicado numa temporalidade social que excede suas próprias capacidades de narração". Além de se ultrapassar o agora, revelamos, ao relatarmos a nós mesmos, elementos que têm uma historicidade. Falar abertamente sobre o "pós-armário", ou seja, um período que sucede a "saída do armário", faz sentido nas atuais condições em que nos encontramos histórica, ideológica e socialmente. Tais condições se referem a uma conjuntura mais "livre", digamos assim, para que alguns sujeitos possam e consigam viver clamando para si identidades gays.

Além disso, as narrativas podem assumir um caráter libertador, pois é por meio delas que sujeitos minorizados podem conseguir algum tipo de visibilidade almejada. Machado (2015a) inclusive enxerga na prática de se narrar uma possibilidade e tentativa de se construir novos traços identitários, menos minorizados, quiçá mais empoderadores.

\section{O ESTRESSE DE MINORIA}

É preciso explicitar que nossa análise aqui, apesar de baseada em apenas dois vídeos, nos oferece pistas relevantes sobre o que temos construído enquanto comunidade e, ainda, nos faz questionar o tipo de estresse a que estamos submetidos a cada dia. Partimos da perspectiva de Hottes et al. (2016), que tratou o estresse de minoria como um problema a ser debatido de modo mais sério. Fomos motivados também pela postagem do jornal "Huffington Post", intitulada "The Epidemics of Gay Loneliness" (tradução nossa: A Epidemia da Solidão Gay), cujo tema central é o estresse de minoria a despeito de diversos direitos adquiridos pela população LGBTQ+ em diferentes partes do mundo no decorrer do tempo. Por fim, um questionamento mais recente foi provocado por Pachankis et al. $(2016,2020)$ a respeito do "intraminority stress", uma espécie de estresse de minoria que ocorre "dentro" da própria comunidade Vol. 03, N. 11, Jul. - Set., 2020 - http://periodicoscientificos.ufmt.br/ojs/index.php/rebeh/index 


\section{준드뉴 \\ REVISTA BRASILEIRA DE ESTUDOS DA HOMOCULTURA}

de pessoas minorizadas. Em que consistiria, então, todo esse estresse e quais seriam seus agentes causadores?

Em entrevista ao site "Them.", Pachankis revelou, como resultado de seu último estudo, quatro fatores de estresse que seriam os principais causadores do "intraminority stress":

Os fatores de estresse que ouvimos nas entrevistas e depois estudamos por todo o país poderiam ser classificados em quatro tipos. Um era o estresse relacionado à percepção da comunidade gay enquanto demasiadamente focada em sexo em detrimento de relacionamentos de longa duração ou amizades. O segundo tipo era que a comunidade gay é muito focada em preocupações relacionadas a status, coisas como masculinidade, atratividade e riqueza. $\mathrm{O}$ terceiro estava relacionado a percepções de que a comunidade é muito competitiva, e que isso sustenta um tipo de cultura do veneno e de competição social geral. O quarto era que a comunidade gay é excludente em diversidade, incluindo diversidade étnico-racial e geracional, além de discriminatória em relação a homens gays com HIV3 (tradução nossa).

Veremos mais adiante que esses mesmos problemas serão apontados por nossos narradores do YouTube. Portanto, mesmo sem conhecerem os estudos do pesquisador mencionado, os homens gays que narraram suas vidas descreveram situações em que esses fatores de estresse levantados por Pachankis fizeram (e fazem) parte de suas vidas.

Michael Hobbes, autor do texto publicado no "Huffington Post", entende o estresse de minoria como o simples fato de, por pertencermos a um grupo minorizado, termos de fazer um esforço extra em diferentes situações na vida, como no trabalho, na escola e na família. A partir daí, ele elenca alguns exemplos presentes tanto em pesquisas, como em pessoas que entrevistou. Menciona, ainda, pessoas próximas, amigos seus que passaram por situações ruins e experienciaram abuso de álcool e outras drogas.

Sabemos desde Goffman (1988, p. 41) que "as pessoas que têm um estigma particular tendem a ter experiências semelhantes de aprendizagem relativa à sua condição e a sofrer mudanças semelhantes na concepção do eu”. Esse senso de comum, de compartilhar os mesmos questionamentos e aprendizagens faz com que possamos pensar a narrativa de vida como um meio de acesso a essas semelhanças. Segundo o mesmo autor, pessoas que se vinculam a uma categoria estigmatizada podem, no

\footnotetext{
${ }^{3}$ Disponível em: https://www.them.us/story/gay-bi-racism-looks-grindr-anxietydepression?utm_source=facebook\&utm_brand=them\&utm_medium=social\&utm_social-type $=$ owned. Acesso em: 20 jul. 2020.
}

Vol. 03, N. 11, Jul. - Set., 2020 - http://periodicoscientificos.ufmt.br/ojs/index.php/rebeh/index 
decorrer do tempo, estender suas relações com as categorias antigas. Isso quer dizer que, no caso do nosso corpus, homens que se entendem como gays carregam consigo problemas de uma vivência em uma sociedade heteronormativa. Estendendo-nos um pouco mais, Alencar e Almeida (2019) apontam que esses mesmos sujeitos, após "saírem do armário", reconhecem que existe muito o que de descontruir ainda em suas vidas - a "saída" implicou a "entrada" em outros universos de significação e de restrição.

O que queremos esclarecer é que o estresse de minoria é a somatização de diversas experiências constrangedoras na vida de um indivíduo minorizado. Essa exposição, inevitável numa sociedade hegemônica cujos parâmetros de hierarquização das sexualidades estão bem definidos, acompanhada da maneira como cada indivíduo vai geri-la, gera como resultado quadros clínicos de depressão, ansiedade, uso abusivo de drogas e até suicídio, como apontam as pesquisas de Pachankis et al. $(2016,2020)$ e de Hottes et al. (2016). Aos poucos, vamos percebendo que a sexualidade não nos liberta, senão aprisiona em novos modos sociodiscursivos. Como bem aponta Miskolci (2011), o Estado ainda se encarrega de enxergar essas identidades enquanto controláveis, assim como o mercado, que as insere em novas formas de consumo.

Ficamos, assim, diante de uma situação que nos vemos pouco libertados, pouco agentes e frustrados com essa ilusão prévia de uma "resolução" de problemas percebemos, a um alto preço, que tudo isso não passa de mais uma série de constrangimentos que ainda teremos de passar. A "saída do armário", por exemplo, está diretamente relacionada ao estresse de minoria, uma vez que essa não libertação da sexualidade pode ser percebida após a "aquisição" de uma identidade de "fora" do armário. Halperin (1995, p. 30, trad. nossa) afirma que, na verdade, "sair do armário" nos expõe a "um conjunto diferente de perigos e constrangimentos", para o qual talvez não estejamos de fato preparados.

Vejamos, então, como se configura o estresse de minoria nas narrativas analisadas. 
ANÁLISE DAS NARRATIVAS DE VIDA

Primeiramente, é preciso tomar em conta que nossa análise está perspectivada pelos estudos da Linguagem, mais precisamente da Análise do Discurso e da Teoria Semiolinguística de Patric Charaudeau, assim como pelos estudos de gênero e sexualidade encontrados em Halperin (1995, 2012), Sedgwick (1988), Miskolci (2011), entre outros.

As narrativas analisadas provêm de dois países: Brasil e Estados Unidos. Esse recorte se deve ao fato de a tese do autor, que está em andamento, possuir esse mesmo propósito contrastivo. O narrador brasileiro, doravante $\mathrm{NB}$, publicou seu vídeo no YouTube em 2015, intitulado “À procura da felicidade!”. A duração da gravação é de $11 \mathrm{~m} 55 \mathrm{~s}$. O vídeo foi gravado em cores no que nos parece ser a casa do NB. Já o narrador estadunidense, doravante NE, publicou seu vídeo em 2017, sob o título "Being Gay - The Truth" (tradução nossa: Ser gay - A Verdade). A duração exata da gravação é de $5 \mathrm{~m} 10 \mathrm{~s}$.

\section{O narrador estadunidense - "The Negatives of Being Gay"}

Seguindo as orientações da Grade de Análise de Imagens4 proposta por Mendes (2013), damos início à análise da narrativa do estadunidense. Em termos de imagem, o vídeo do NE foi gravado em Primeiro Plano (PP), seguindo a nomenclatura de Vergueiro (2012). O efeito de sentido causado por essa escolha de plano é o de aproximação com o sujeito-interpretante, pois graças a esse plano é possível visualizar os caracteres emocionais do sujeito que narra, assim como parte do ambiente de onde a narrativa se dá. $\mathrm{O}$ ângulo de gravação escolhido foi o médio, fazendo com que a narrativa transcorresse na altura dos nossos olhos. Ambos elementos, plano e ângulo, geram um efeito de proximidade com o sujeito-interpretante.

Ora, se o narrador se propõe a desvendar algo acerca de se ser gay, como o título do seu vídeo nos promete, é realmente necessário que essa revelação seja feita de maneira próxima. E isso ocorre também na linguagem verbal, pois o NE, no início de sua narrativa, já deixa claro seu ponto de vista: “a lot of times I see gay people as

\footnotetext{
${ }^{4}$ Vide Quadro 1.
}

Vol. 03, N. 11, Jul. - Set., 2020 - http://periodicoscientificos.ufmt.br/ojs/index.php/rebeh/index 
portraying this lifestyle as really happy, really positive, and I don't really think people talk about the negative aspects of it" (tradução nossa: muitas vezes, eu vejo as pessoas gays retratando estilos de vida muito felizes, positivos, e eu não acho que as pessoas falem dos aspectos negativos disso). Existe também uma dimensão argumentativa, conforme afirma Charaudeau (2008), nessa afirmação, pois NE quer sair de um lugar comum e nos mostrar que existem fatores negativos envolvidos na experiência de vida gay masculina. Para nos convencer desse argumento, ele irá nos apresentar aspectos talvez comuns, ou que ele imagina que seus sujeitos-destinatários irão compartilhar consigo.

Para fortalecer a credibilidade de sua narrativa, NE faz uso de elementos factuais, ou seja, verdadeiros, que realmente aconteceram com ele. Na linguagem verbal, o percebemos quando ele cita o fato de ter passado o ensino médio "no armário": "I didn't come out in high school, so I wasn't really comfortable with myself, and I still am not comfortable with myself” (tradução nossa: eu não saí do armário no ensino médio, então eu não estava totalmente confortável comigo mesmo, e ainda não estou). $\mathrm{Na}$ linguagem não verbal, os elementos factuais nos são apresentados por meio da própria apresentação sua em cena, em cores, num ambiente que parece ser sua casa.

O estrato sonoro é um dos elementos que constam na Grade de Análise de Imagens. É importante percebermos que, na narrativa do NE, não há outro som senão sua voz. Isso quer dizer que sua possível intencionalidade seja que nos atentemos exclusivamente ao que ele vai dizer, o que tem estreita relação com o plano e ângulo escolhidos, como vimos anteriormente. É como se estivéssemos diante do NE, e tudo o que importa naquele momento é ouvi-lo. O único momento de silêncio existente está nos primeiros segundos do vídeo, quando é projetado o título "The Negatives of Being Gay" (tradução nossa: As partes negativas em ser gay). A falta de som também tem significação, pois, novamente, a atenção do sujeito-interpretante se volta à linguagem verbal, ou seja, à leitura daquele título.

Dentre os modos de organização do discurso propostos por Charaudeau (2008), o narrativo é predominante, mas existe ainda o argumentativo, como já apontamos. $\mathrm{O}$ NE quer nos provar alguns pontos que são de interesse dos estudiosos de gênero e sexualidade, como quando trata de uma vida "fora do armário": "some people make it 
seem like it's just like... And... you're fine, you come out of the closet and it's A-okay, you're fully accepting of yourself all of a sudden" (tradução nossa: algumas pessoas fazem parecer que é tipo...E pronto, você está bem, você sai do armário e está tudo bem, você se aceita completamente de repente). Aqui ele trata justamente desse estresse de minoria, de pessoas que já estão "fora", mas não se veem tão libertas assim. Segundo Halperin (1995), o armário é um lugar contraditório, pois nunca estamos totalmente dentro, nem fora dele. Existe uma constante negociação de visibilidades: como o NE menciona, há situações em que ele não se sentiria confortável em beijar ou segurar as mãos de um homem em público.

Toda essa situação inescapável deixa o NE triste, pois, segundo ele, há coisas que ele consegue mudar em si mesmo, como o estilo de roupa, enquanto a sexualidade é algo imutável: "your sexuality isn't something that you can just flip a switch and change. It's something you have to live with and deal with everyday" (tradução nossa: sua sexualdiade não é algo que você consiga liga/desligar e mudá-la. É algo que você tem que conviver e lidar todo dia). A sexualidade é um dispositivo já estabelecido na sociedade atual em termos de Foucault (1988). Desde o século XIX, estabeleceu-se uma demanda por uma verdade sobre os sexos, orientada sob a égide do que o filósofo denominou uma scientia sexualis. Se hoje vivemos essa inescapabilidade da sexualidade, talvez seja pelo fato de sermos já um subproduto dessas relações discursivas e de poder que colocam a sexualidade como algo de que se deve falar, mostrar exaustivamente.

A sexualidade opera, ainda, em um nível em que talvez nunca nos sintamos totalmente confortáveis com ela, sobretudo em casos de sexualidades dissidentes. O NE descreve justamente isso:

I'm afraid that I will never be comfortable with myself, and a lot of people say "just fully come out of the closet." Actually I've read a comment that said "just fully come out, and you'll feel so much better." But that isn't the case, because even if I come out, I'm still gonna feel uncomfortable with myself, and you may, too! (PHOENIX, 2019)

Tradução nossa:

Eu temo nunca me sentir confortável comigo mesmo, e muitas pessoas dizem "apenas saia totalmente do armário". Na verdade, eu já li um comentário que dizia "saia totalmente do armário e você se sentirá muito melhor". Mas esse não é o caso, porque mesmo se eu sair, eu ainda vou me sentir desconfortável comigo mesmo, e o mesmo pode acontecer com você! 
Sabemos, desde Sedgwick (1990, p. 81), que o armário é uma estrutura infindável. Por isso, "To come out does not end anyone's relation to the closet" (tradução nossa: sair do armário não finda a relação de alguém com o armário). E é justamente isso que o NE descreve: uma sensação de que sua relação com o armário nunca irá terminar. Haveria, assim, um eterno desconforto propiciado por esse sentimento de não pertencimento à ordem social hegemônica, o que pode acarretar, segundo as pesquisas citadas no campo da Psicologia, o estresse de minoria. Para Wilson \& Cariola (2019, p. 14), trata-se da "marginalização", o que elas definem como "the socio-political status of a population sub-group such as LGBT experiencing diminished community acceptance and systemic discrimination" (tradução nossa: o status sociopolítico de um subgrupo da população, como a LGBT, que experiencia uma aceitação comunitária reduzida e uma discriminação sistêmica). O simples fato de pertencermos a esse subgrupo já nos colocaria, pois, em uma situação sistêmica de discriminação.

\section{O narrador brasileiro - "À procura da felicidade"}

O narrador brasileiro (NB) apresenta outros questionamentos igualmente importantes. Primeiramente, em termos de imagem, o vídeo do NB foi gravado em Primeiro Plano (PP). O ângulo de gravação foi o inferior, utilizado quando se quer enaltecer o sujeito em destaque.

Bom, ao analisarmos a narrativa, percebemos que é importante para o NB se aproximar de seu público. O próprio título de seu vídeo nos antecipa um tema que está no universo do patêmico, ou seja, relacionado à emoção. O enaltecimento de seus caracteres, logrado pela escolha de ângulo, também é pertinente, uma vez que, após relatar ter sofrido de depressão, como nos relata no vídeo, no momento em que grava e publica seu vídeo o narrador se mostra como alguém "melhor", mais ou menos superado.

Para chegar até esse estágio, o NB se questionou muito a respeito de vários aspectos de sua vida. "Eu sempre me senti diferente de todo mundo!", afirma em um momento da narrativa. Acrescenta ainda: "E isso foi me travando muito, assim, eu tive muita dificuldade de fazer amizade com pessoas". Sentir-se diferente pode significar Vol. 03, N. 11, Jul. - Set., 2020 - http://periodicoscientificos.ufmt.br/ojs/index.php/rebeh/index 
não se identificar com o que a maioria das pessoas estão praticando e valorando.

Segundo Halperin (2012), ser gay perpassa essa desidentificação, que é uma sorte de afastamento crítico das práticas sociais já estabelecidas sob um olhar não normativo.

Esse afastamento, por exemplo, é sentido desde a escola, como o narrador pontua: "eu tinha colegas de escola, mas eu não conseguia ir além disso". O período escolar é bastante problemático e relatado por todos nossos narradores que compõem o corpus da tese em andamento. A instituição escolar é denominada instituição de sequestro, segundo Foucault (2013), pois é nela onde os corpos são já disciplinados e docilizados, além de submetidos a um regime de visibilidades que separa meninos de meninas, os mais aptos dos menos aptos.

Tanto na linguagem verbal como na não verbal observamos a configuração de um estatuto factual, com efeitos de real, segundo a grade de Mendes (2013). Isso quer dizer que aquilo que o narrador mostra e diz estão no universo do possível, do factível, pois tudo o que relata possivelmente aconteceu, de fato, consigo. Trata-se de lembranças que podem gerar identificações no espectador, seu sujeito-interpretante, uma vez que as afirmações do NB são carregadas de emoções, como mencionamos acima. Segundo Machado (2015), o patêmico tem forte poder persuasivo, por vezes mais forte do que um gênero argumentativo propriamente dito, carregado de logos. Portanto, através de suas emoções, o NB consegue fazer-nos crer na importância de sua narrativa.

Ainda a respeito disso, na linguagem não verbal constatamos o factual na gravação do narrador, que foi feita por uma câmera que gera imagens em cores e em um ambiente que parece ser sua casa. Temos a dimensão de algo real em sua vida, mostrada graças ao ângulo e planos escolhidos pelo NB. Na linguagem verbal, o factual se junta ao emotivo, e o efeito gerado é o de nos colocarmos no lugar do narrador. Uma das maneiras que o fazem conseguir tal efeito é a inserção das vozes de terceiros na sua própria narrativa. Essas vozes podem ser realmente de terceiros ou de seu outro eu, que dialoga com o sujeito empírico. Vejamos os exemplos:

Chegou um momento em que eu me vi totalmente sem amigo, sem ninguém, e era muito difícil, assim...Eu lembro de algumas cenas, assim, que algumas pessoas da minha família falavam assim, é...: “ai, Fernando! Faz alguma coisa! Ai, se diverte! Você não tem amigo nenhum, meu. Para pra pensar, você não tem amigo nenhum!".

Vol. 03, N. 11, Jul. - Set., 2020 - http://periodicoscientificos.ufmt.br/ojs/index.php/rebeh/index 
Eu queria mesmo creditar que eu era hétero de todos os jeitos, de todas as maneiras. Eu falava "meu, eu não posso ser isso! Não é! Tem alguma coisa errada, isso é coisa da minha cabeça, vai passar".

No primeiro caso, temos a voz da sua família, que o NB reproduz de modo a nos fazer pensar que é realmente ela quem fala. Apesar de a família representar algo compósito, conseguimos imaginar os membros dela proferindo aquelas palavras ao narrador. Obviamente, a voz do próprio narrador pode estar ali nas palavras da família, pois sabemos que é impossível garantirmos uma verdade única - as vozes se misturam, são polissêmicas. Segundo Machado (2016, p. 121), o eu-narrador “nunca é uno e sim construído por outras vozes ou fragmentos de vozes". Tal afirmação pode assumir dois sentidos: primeiramente, o de que o eu-narrador funciona como uma instância compósita, ou seja, dentro de um "eu” existem diversas vozes e, em segundo lugar, de que as vozes que compõem esse "eu" são manifestadas na fala do próprio eu-narrador, que não consegue assegurar até que ponto o que diz lhe pertence ou pertence a outrem.

Já no segundo exemplo, é clara a inserção dos pensamentos do narrador na própria fala. Butler (2015) nos lembra que não há criação sem subjetivação, ou seja, o sujeito deve assumir formas que já existem para "se criar". A negação do NB sobre si mesmo é constituída pela não visão de si nos outros, pois ser hétero era algo que já existia. Portanto, como ser algo que não existe? Esse conflito é bem representado pelo narrador no excerto da narrativa supracitado.

Dando seguimento à grade de análise de imagens, os modos de organização do discurso predominantes são o narrativo e o argumentativo. O NB nos situa sobre sua trajetória em relação a aceitação de si mesmo, sua "procura da felicidade", que tem início na escola e se encontra finalmente com sua mudança para a cidade de São Paulo e sua "saída do armário" para a família e os amigos. Existem aí elementos característicos da narrativa, como o decorrer do tempo, "personagens", lugares, todos sequenciados. Na linguagem não verbal, percebemos esse "passar do tempo" pelo próprio vídeo, pela movimentação do NB, suas expressões faciais, e pela própria movimentação do cursor do YouTube no quadro de vídeo. O modo argumentativo, como apontamos anteriormente, se dá sobretudo pela emoção, pela construção de um cenário de muita batalha pessoal para se chegar a um momento de realização: "Hoje em dia, eu tô muito mais tranquilo, e eu vi que, tipo, mano, encontrei, assim, o meu eu interior, sabe?”. Ao 
narrar seu passado carregado de emoções negativas, o NB descreve também um presente mais tranquilo e em paz consigo mesmo. Para provar isso, afirma que agora tem amigos, sai de casa com frequência e encontrou na Internet uma maneira de se expressar e de ser amplamente aceito.

Aliás, foi pela Internet também sua "saída do armário" para parte de sua família, pois vivia longe deles. Nas palavras do NB, “É...foi tudo muito...é, tecnológico, porque foi tudo pro WhatsApp. Recebi alguns áudios e tal, da galera...é, foi muito tranquilo, assim. Minha família é muito de boa com isso". Segundo Bruno (2013, p. 68), o ambiente virtual tem se tornado o inaugurador de algumas experiências de vida de alguns sujeitos, como no caso do narrador brasileiro. Além disso, afirma que "nas práticas de visibilidade contemporâneas", a intimidade "se volta para fora, num movimento de conquista de um olhar que lhe proporcione a visibilidade requerida". Foi, de fato, o que ocorreu com o NB, que afirma ter tido sua vida completamente mudada graças à Internet quando começou postando vídeos no Vine, depois no Snapchat e no YouTube: "a internet mudou minha vida! E eu passei a ter mais coragem de enfrentar as coisas." Suas intimidades, agora publicizadas, ganharam a visibilidade que ele desejava, e foram moldadas de forma que seus sujeitos-destinatários pudessem, de alguma maneira, se identificar com o que ele expunha na rede.

Por fim, no estrato sonoro percebemos que, assim como ocorreu com o NE, a voz foi o elemento mais importante na narrativa. Parece óbvio, mas em outros exemplos analisados na tese em andamento, efeitos sonoros incluídos na gravação foram observados, o que causa efeitos de sentido particulares. Observamos ainda em outras narrativas o som do ambiente público onde um narrador se encontrava, o que também causou outros efeitos. De qualquer modo, o NB possui um tom de voz constante, mesmo quando "dá voz" à sua família, como vimos acima, e quando descreve seus pensamentos. Toda essa estabilidade faz sentido, uma vez que, por agora se encontrar em um estágio de superação e de "encontro com a felicidade", o NB projeta um ethos de realizado, de que cumpriu sua trajetória de forma satisfatória. Não se encontra exaltado, e sim consciente de seu caminho, do que passou e do que ainda tem pela frente.

Apesar de o NB não ter relatado elementos do "intraminotiry stress", percebemos em sua narrativa um sentimento de solidão no passado por ter vivido a 
adolescência sem amigos e de ter vivido "no armário" para sua família e amigos. Além disso, talvez pelo fato de sua "saída" ter sido recente, o NB não se questiona muito sobre a comunidade de homens gays de que participa - suas preocupações são sobretudo centradas nas questões do passado. Existe, ainda, uma certa ilusão de que suas sexualidades não interferirão na sua experiência de vida em outros meandros, como vimos no seguinte trecho em que caracteriza suas homossexualidades: "uma coisa que nasceu com você e que não interfere em nada: no seu trabalho, na sua vida, nas suas amizades, na pessoa que você é no mundo".

Ora, o que não podemos negar é que toda essa trajetória penosa por que passou o NB seguramente modifica suas relações com o outro no trabalho, nas amizades, na sua vida. Ao pensarmos que nossas sexualidades dizem respeito a algo particular, subjugamos nossas habilidades de questionar a ordem vigente, pois é possível se inadequar, subverter. Talvez uma outra característica do estresse de minoria resida no fato de termos, enquanto grupo minorizado, de buscar sempre estar se enquadrando em modos de vida com que não nos identificamos. Assim, nossa longa trajetória de desidentificações, iniciada lá na infância/adolescência não se finda, nem com a "saída do armário".

\section{CONSIDERAÇÕES FINAIS}

A saúde mental da população LGBTQ+ deve ser amplamente discutida partindose de diversas áreas do conhecimento. Temos constatado que, a despeito de garantias legais como o casamento igualitário, arduamente conquistadas durante a história a custa de perdas de vidas em protestos, negligência sanitária e assistencial, existe muito ainda a se viabilizar para que nossas vidas se tornem menos constrangidas.

É preciso, cada vez mais, lançar mãos de outros vieses de abordagem para questões de gênero e sexualidade ainda que partamos da Psicologia, Biologia e Medicina. Talvez assim possamos seguir um caminho em direção à maior legitimação de nossas áreas de estudos no campo das Humanidades. As narrativas de vida provaram ser um mecanismo linguístico pertinente para lançarmos novos olhares sobre as experiências de pessoas minorizadas, que lidam com suas sexualidades dissidentes de 
modos particulares mas que dizem muito a respeito de como a sociedade - tanto hegemônica, como sua própria comunidade - as trata.

A respeito das narrativas, constatamos que, apesar de os narradores se encontrarem em estágios distintos em termos de experiências de vida, o NB retratou muito seu estresse enquanto pessoa "no armário". Prospectou ainda uma visão muito positiva em relação à sua vida "fora"; o que, por outro lado, o NE mostrou não ser tão libertador ainda. Precisamos repensar, questionar e discutir os "armários" da vida, ou seja, os espaços em que nós, população LGBTQ+ nos sentimos ainda limitados, embaraçosos de frequentarmos. Até que ponto isso têm afetado nossa saúde mental? Quais seriam os novos desafios de um engajamento frente a algo que não é exclusivamente político e palpável, como direitos sob a lei, mas algo subjetivo, como o estresse? Talvez esses sejam nossos atuais questionamentos se quisermos continuar avançando por modos de vida mais vivíveis.

\section{REFERÊNCIAS}

ALENCAR, Venan L. O; ALMEIDA, Daniel M. V. "As narrativas do pós-armário no YouTube: discurso, cultura e subjetividades". Gláuks: Revista de Letras e Artes jan/jun. 2019 - Vol. 19, Nº 1, pp. 199-218.

BRUNO, Fernanda. Máquinas de se ver, modos de ser: vigilância, tecnologia e subjetividade. Porto Alegre: Sulina, 2013.

BUTLER, J. Relatar a si mesmo: crítica da violência ética. Trad. Rogério Bettoni. Autêntica: e-book Kindle, 2015.

CHARAUDEAU, P. "Uma teoria os sujeitos da linguagem". In. Hugo Mari, Ida Lucia Machado, Renato de Mello. Análise do discurso: fundamentos e práticas. Belo Horizonte : Nad-FALE-UFMG, 2003.

CHARAUDEAU, P. Linguagem e discurso: modos de organização. Trad. Angela M.

S. Correa \& Ida Lucia Machado. São Paulo: Contexto, 2008.

ESCARIÃO, Fernando. À procura da felicidade! 2015. (11m55s). Disponível em: <https://www.youtube.com/watch?v=OGMs9oR1Z3s >. Acesso em: 26 jun. 2019.

FOUCAult, M. Discipline and Punish: The Birth of the Prison, trans. Alan Sheridan (New York: Vintage, 1978).

FOUCAULT, M. História da sexualidade I: a vontade de saber. Rio de Janeiro: Edições Graal, 1988.

FOUCAULT, M. Vigiar e Punir: O nascimento da prisão. Trad. Pedro Elói Duarte. Lisboa: Edições 70, 2013.

Vol. 03, N. 11, Jul. - Set., 2020 - http://periodicoscientificos.ufmt.br/ojs/index.php/rebeh/index 
HALPERIN, David M. Saint Foucault: Towards a Gay Hagiography. Oxford University Press. New York, NY, 1995.

HALPERIN, David. M. How to be gay. Cambridge, Massachusetts: Belknap Press, 2012.

HOTTES, Travis Salway; FERLATTE, Olivier; DULAI, Joshun. "Preventing Suicide among gay and bissexual men: new research \& perspectives". Report presented by the Community-based Research Center for Gay Men's Health to the Public Health Agency of Canada. September 2016.

MACHADO, I.L. "A narrativa de vida como materialidade discursiva". Revista ABRALIN, v. 14, n. 2, p. 95-108, jul./dez. 2015.

MACHADO, I. L. "A narrativa de vida como uma tentativa de construção da identidade". IN: LARA, Gláucia Proença e LIMBERTI, Rita (Org.). Discurso e (Des)Igualdade Social. São Paulo: Contexto, 2015a.

MACHADO, I.L. "Nos bastidores da Narrativa de vida \& Análise do Discurso". In: MACHADO, I.L. e MELO, M.S.S. (org.) Estudos sobre narrativas em diferentes materialidades discursivas. Belo Horizonte: NAD/FALE/UFMG, 2016, p. 121-138. (Disponível em: http: www.letras.ufmg.br/nucleos/nad).

MENDES, E. "Análise do discurso e iconicidade: uma proposta teórico-metodológica". In: Imagem e Discurso. Mendes, E. (coord.) Belo Horizonte: FALE/UFMG, 2013.

MISKOLCI, Richard. "Não somos, queremos - Reflexões queer sobre a política sexual brasileira contemporânea". In: Stonewall 40 + o que no Brasil? / Leandro Colling, organizador. - Salvador : EDUFBA, 2011. 282 p. - (Coleção CULT; n. 9).

PACHANKIS, John E.; ELDAHAN, Adam I.; GOLUB, Sarit A. "New to New York: Ecological and Psychological Predictors of Health Among Recently Arrived Young Adult Gay and Bisexual Urban Migrants”. Ann Behav Med. 2016 Oct; 50(5): p. 692703. doi: 10.1007/s12160-016-9794-8.

PACHANKIS, J. E., CLARK, K. A., BURTON, C. L., HUGHTO, J. M. W., BRÄNSTRÖM, R., \& KEENE, D. E. (2020). "Sex, status, competition, and exclusion: Intraminority stress from within the gay community and gay and bisexual men's mental health". Journal of Personality and Social Psychology. Advance online publication. https://doi.org/10.1037/pspp0000282.

PHOENIX. Being Gay - The Truth. 2017. (5m10s). Disponível em: https://www.youtube.com/watch?v=EvFW7q9CRTU. Acesso em: 26 jun. 2019.

SEDGWICK, Eve K. "Introduction: Axiomatic" (excerpt) and "Epistemology of the Closet" (1988). Epistemology of the Closet. Berkeley: University of California Press, 1990, p. 1-11, 67-90;

Site Huffington Post. Disponível em: https://highline.huffingtonpost.com/articles/en/gay-loneliness/. Acesso em: 20 mar. 2017. 
Site Them. Disponível em: https://www.them.us/story/gay-bi-racism-looks-grindranxietydepression?utm_source=facebook\&utm_brand=them\&utm_medium=social\&ut m_social-type=owned. Acesso em: 20 jul. 2020.

VERGUEIRO, Waldomiro. "A linguagem dos quadrinhos: uma alfabetização necessária". In: RAMA et al. Como usar as histórias em quadrinhos na sala de aula. 4 ed. $1^{a}$ reimpressão. São Paulo: Contexto, 2012, p. 31-64)

WILSON, Claire; CARIOLA, Laura A. "LGBTQI+ Youth and Mental Health: A Systematic Review of Qualitative Research". Adolescente Research Review. https://doi.org/10.1007/s40894-019-00118-w. Published online 21 May 2019.

\section{MINORITY STRESS AND LIFE NARRATIVES OF GAY MEN ON YOUTUBE}

Abstract: Life narratives make it possible to denounce, expose, or evidentiate some problems concerning not only the individual who narrates but also the community they participate in. In this study, our goal is to analyze two life narratives available on YouTube using the French Discourse Analysis. In addition to the analysis of verbal language, we aimed to draw parallels between verbal and non-verbal language using an Image Analysis Grid proposed by Mendes (2013). Thus, our research has both a linguistic and iconic departure points crossed by gender and sexuality issues. Halperin (1995, 2012), Foucault (1978, 1988), and Hottes et al. (2016) are some of the authors we have called on to understand what our narrators brought up in their speech. Regarding life narratives, thoughts of Machado $(2015,2016)$ were added to this study, for she widens up our notions on the theme and allows us to think beyond the linguistic materiality. Overall, we hope this short analysis sheds some light on constrained life modes of minorities so that we can luckily deepen the particularities of our ways of life, questioning and bringing to the surface some not-so-obvious issues.

Keywords: Discourse Analysis, Life Narratives, Minority Stress, YouTube.

Recebido: 04/08/2020.

Aceito: 06/10/2020. 